\title{
Neurological Complications of Hypertension: A Review
}

\section{Article}

\author{
Visaliini Ganapathy ${ }^{1}$, Nasrin Habib ${ }^{2 *}$, Farzana Afzal ${ }^{3}$ and Mamunur \\ Rashid 4 \\ ${ }^{1}$ Faculty of Medicine, QUEST International University, Malaysia \\ ${ }^{2}$ Department of Physiology, Faculty of Medicine, QUEST International University, \\ Malaysia \\ ${ }^{3}$ Departments of Oculoplasty, Ispahani Islamia Eye Institute and Hospital, Bangladesh \\ ${ }^{4}$ Department of Medicine, Faculty of Medicine, QUEST International University, Malaysia
}

\section{Review article}

Volume 3 Issue 2

Received Date: July 06, 2019

Published Date: August 02, 2019

DOI: $10.23880 /$ phoa-16000141

*Corresponding author: Nasrin Habib, Department of Physiology, Faculty of Medicine, QUEST International University, Malaysia, Email: drnh@gmail.com

\section{Abstract}

Hypertension (HTN) is a major cause of morbidity and mortality because of its complication like neuronal disease, coronary heart disease, cerebrovascular disease and renal disease. It is also known for the second most common cause of death after diabetes in adults worldwide. This study is mainly focus on neurological complications due to HTN. The reason is to improve patient's quality of life and at the same time to increase their life span by knowing the causes and prevention methods. Epidemiology of HTN also need to be taken into concern, as it is important to reduce HTN not only in Malaysian, also people throughout the world. Neurological complication like stroke has shown an encouraging improvement in patient those who are under medications such as antihypertensive drug, physiotherapy and also rehabilitation.

Keywords: Hypertension; Stroke; Hypertensive Encephalopathy; Hypertensive Retinopathy; Eclampsia; Blood Pressure; National Health And Morbidity Surveys; Cardiac Output

Abbreviations: SBP: Systolic Blood Pressure; HTN: Hypertension; BP: Blood Pressure.

\section{Introduction}

Each and every individual have their own way of lifestyles to lead their lives in the sense of healthy living. To most people healthy living means both physical and mental health are in balance or functioning well together in a person. In many instances, physical and mental health are closely linked, so that a change like good or bad in one directly affects the other. In relation to that, some people have a good diet in their daily life and also actively involved in physical activities like exercise to keep themselves fit. However, some people do not bother and at the same time does not have the knowledge on their health where they may not have a good eating habits and also exercise or either one. These are one of the 
modifiable factors which may lead to HTN. Other than that, age, race, genetic factors and also environmental factors has the higher risk of getting HTN. HTN was recognized as an indicator of poor prognosis by Theodore Janeway, who published a case series of 7,872 hypertensive patients gathered between 1903 and 1912, in which HTN was defined as a systolic blood pressure (SBP) greater than $160 \mathrm{mmHg}$ [1]. According to Sharifian $M$ and Iran J, HTN is the second most common cause of death after diabetes in adults worldwide [2]. Some authors call it as silent killer as there is no significant symptoms for HTN. Hypertension is serious because people with the condition have a higher risk for heart disease and other medical problems than people with normal blood pressure (BP). Serious complications can be avoided by getting regular BP checks and treating HTN as soon as it is diagnosed [3].

If left untreated, HTN can lead to the following medical conditions such as atherosclerosis, heart attack, stroke, enlarged heart, kidney damage and one of it is neurological complications. Based on the author Caronna and Cuneo, they proposed that neurological complications of HTN could be classified into 3 syndromes (hypertensive encephalopathy, lacunar infarction, and hypertensive hemorrhage) which differ clinically but share the same underlying pathological process [3]. Regardless of a person whether they are young or adult, the HTN with neurological complications occur. In that case, there are various neurological complications due to HTN need to be taken into concern $[4,5]$.

\section{Neurological Complications Due to Hypertension}

As HTN is common in any age group, there are various neurological complications occur in younger and older people with HTN. In children, the incidence of severe arterial hypertension is unknown and it is uncommon [6]. The neurological complications in hypertensive children are facial paresis, acute hemiplegia, and hypertensive encephalopathy. In general, there are 3 clinical syndromes of neurological complications unique to HTN result like hypertensive encephalopathy, lacunar infarction, and hypertensive hemorrhage [7]. So, the importance of measuring BP in adults with neurological symptoms is more widely appreciated than in children, possibly due to a lack of information among pediatricians. Over and above that, neurological complications also occur in a pregnant woman who is suffering from high BP which is known as eclampsia [7].

\section{Stroke Due to Hypertension}

Stroke is the highest prevalence neurological complications of HTN. It is a sudden onset of weakness, numbness, paralysis, slurred speech, blurred vision and other features of a sudden interruption in flow of the blood at a specific area of the brain. HTN is the primary pathophysiologic condition in stroke and at the same time it is a modified risk factor. So, it can be reduced by decreasing patient's high BP. Stoke can be classified into ischemic and hemorrhagic stroke which are contributed by HTN including carotid stenosis, intracranial atherosclerosis, small-vessel arteriosclerosis, and both macroscopic and microscopic aneurysms [8].

HTN can cause stroke through various mechanisms such as high intraluminal pressure will lead to extensive alteration in endothelium and smooth muscle function in intracerebral arteries. The increased stress on the endothelium also can increase permeability over the blood-brain barrier and forms local or multifocal brain edema. Endothelial damage and altered blood cellendothelium interaction can lead to local thrombi formation and ischemic lesions. In addition, fibrinoid necrosis can cause lacunar infarcts through focal stenosis and occlusions. Degenerative changes in smooth muscle cells and endothelium predisposes for intracerebral hemorrhages [7].

The pathophysiology of stroke which is caused by HTN is due to increase in sympathoadrenal tone with subsequent release of renin and vasoconstriction of arterioles results from direct injury to inhibitory or modulatory brain regions [8]. As a result, it leads to impaired cardiac baroreceptor sensitivity in patients associated with stroke [1]. In ischemic stroke, which is the result of cerebral ischemia, HTN play a compensatory role in maintaining the cerebral perfusion. It has been demonstrated that loss of normal cerebral autoregulation in areas of ischemic brain. Blood flow to the brain becomes directly proportional to mean arterial pressure when autoregulation is lost due to cerebral ischemia. Therefore, it is stated in a theory that pharmacologic increases in BP could have salutatory effects in preserving hypo perfused regions of the brain [1].

Next, the hemorrhagic stroke is caused by HTN associated with cerebral aneurysm formation and subarachnoid hemorrhage where increase in BP causes increase intracranial pressure. As the pressure exceed its limited level, the arteries will rupture at the subarachnoid space which leads to hemorrhage [2]. 


\section{Hypertensive Encephalopathy Due to Hypertension}

The hypertensive encephalopathy is one of the neurological complication consisting of a sudden elevation of arterial pressure usually presented by severe headache and followed by convulsions, coma or a variety of transitory cerebral phenomena. It is also one of several forms of posterior reversible encephalopathy which is also encompassing other causes like renal failure, immunosuppressive therapy and eclampsia [1]. Moreover, hypertensive encephalopathy is a neurologic emergency that can lead to death if untreated. Diagnosis may be delayed when the connection between acute neurologic dysfunction and HTN is not obvious. High BP may be attributed to an underlying neurologic condition or agitation rather than identified as the causative agent [1]. In this headache is a common early complaint, sometimes accompanied by nausea and vomiting. The pathophysiology of hypertensive encephalopathy is due to increased cerebral perfusion from the loss of bloodbrain barrier integrity, which results in exudation of fluid into the brain [9]. In normotensive individuals, an increase in systemic blood pressure over a certain range of $60-125 \mathrm{~mm} \mathrm{Hg}$ induces cerebral arteriolar vasoconstriction, whereby preserving a constant cerebral blood flow and an intact blood-brain barrier. The cerebral autoregulatory range is gradually shifted to higher pressures as an adaptation to the chronic elevation of systemic blood pressure in a chronic hypertensive patient [2].

\section{Hypertensive Retinopathy Due to Hypertension}

Hypertensive retinopathy is also one of the neurological complications of HTN where it causes retinal vascular damage. Over a period of time, high BP put its pressure on the optic nerve, causing vision problem by limiting the retinal function. Hypertensive retinopathy classified by mild, moderate and malignant depending on the strength of their associations with systemic vascular disease. Mild is generalized or focal arteriolar narrowing, arteriovenous nicking and increased arteriolar opacity [10]. Whereas moderate means retinal microaneurysm or hemorrhage, cotton wool spot and hard exudates while malignant define as moderate retinopathy and optic disk swelling. On top of that, hypertensive retinopathy is also divided into acute and chronic hypertensive retinal changes. In acute hypertensive retinopathy, optic disc edema is the primary manifestation [11]. The blood supply to the optic nerve arrives via posterior ciliary arteries and peripapillary choroidal vessels. So, the vasoconstriction and choroidal ischemia in the setting of malignant hypertension result in optic disc edema and axoplasmic flow stasis. In chronic hypertensive retinopathy, optic disc pallor develops. Due to the frequent coexistence of HTN and diabetes, diabetic and hypertensive eye complications may also be seen together [10].

\section{Eclampsia in Pregnancy Due to Hypertension}

Eclampsia is a severe neuronal complication in pregnant woman where high BP results in seizures. Seizures are periods of disturbed brain activity that can cause episodes of staring, decreased alertness and convulsions during pregnancy. However, the pathogenesis of these complications such as eclamptic seizures, coma, visual disturbances and localizing neurological defects remains poorly understood [12]. Even though the endothelial dysfunction is likely to make a significant contribution but the pathophysiology of underlying eclamptic seizures remain to be elucidated [13].

There are two theories have been proposed based on different hypothesis regarding the cerebrovascular response to systemic hypertension. Firstly, cerebral "overregulation," leading to vasospasm, ischemia, and intracellular edema. And the next one is the loss of cerebral autoregulation, leading to hyper perfusion, extracellular edema and the posterior reversible encephalopathy syndrome [13].

\section{Treatment and Management for Hypertension Associated with Neurological Complications}

HTN contributes to major complications like carotid stenosis, intracranial atherosclerosis, and neuronal effects such as ischemic and hemorrhagic stroke, cerebral aneurysm and so on. But there are certain ways to reduce the rate of mortality caused by HTN associated with neurological complications. For that HTN need to be prevented from each and every individual by Recommendation of lifestyle modification is an initial therapy for patients with BP of $120 / 80 \mathrm{mmHg}$ or higher. Effective lifestyle includes weight loss, carry out physical activity, reduction in sodium intake, adequate potassium intake, avoid smoking and consuming alcohol and also dietary regimens [4]. Antihypertensive medications are recommended in addition to lifestyle measures for patients with blood pressure of $140 / 90 \mathrm{mmHg}$ or higher, with a lower threshold of $130 / 80 \mathrm{mmHg}$ or higher in those with diabetes and chronic kidney disease [14]. For patients without a history of cardiovascular disease or other compelling indication, initiating therapy with a thiazide diuretic such as chlorthalidone is generally 
recommended. When the $\mathrm{BP}$ is $160 / 100 \mathrm{mmHg}$ or higher, initiating therapy with two-drug combinations is generally recommended [1].

The agents that are recommended by the American Stroke Association (ASA) for acute hypertensive response are either intravenous or transdermal agents with rapid onset and short duration of action to allow precise titration. Table 1 shows the pharmacological characteristics of antihypertensive agents recommended by American Stroke Association [8].

Pharmacological characteristics of antihypertensive agents recommended by American Stroke Association (ASA)

\begin{tabular}{|c|c|c|c|c|c|c|c|c|c|c|c|}
\hline Agent & $\begin{array}{c}\text { Mechanism } \\
\text { of action }\end{array}$ & CBF & ICP & $\begin{array}{c}\text { Autoreg } \\
\text { ulation }\end{array}$ & $\begin{array}{c}\text { Platelate } \\
\text { activity }\end{array}$ & $\begin{array}{c}\text { Cardiac } \\
\text { Contractivity } \\
++\end{array}$ & Dose & $\begin{array}{l}\text { Onset of } \\
\text { action }\end{array}$ & Half life & $\begin{array}{l}\text { Ischemic } \\
\text { Strock }\end{array}$ & ICH \\
\hline $\begin{array}{c}\text { Labetalo } \\
1\end{array}$ & $\begin{array}{l}\infty \text { and } \beta- \\
\text { Andrenerg } \\
\text { ic blocker }\end{array}$ & $\ldots$ & $\ldots$ & $\ldots$ & - & $\ldots$ & $\begin{array}{c}5-20 \mathrm{mg} \\
\text { bolus every } \\
15 \mathrm{~min} \text { up to } \\
300 \mathrm{mg}\end{array}$ & $\begin{array}{c}5-10 \\
\text { min }\end{array}$ & $3-6 \mathrm{~h}$ & $\begin{array}{c}\text { SS, CS, }{ }^{42} \\
\mathrm{ES}^{87}\end{array}$ & $\begin{array}{l}\text { SS, CS, } \\
82,88 \\
\mathrm{ES}^{89}\end{array}$ \\
\hline $\begin{array}{l}\text { Hydralaz } \\
\text { ine }\end{array}$ & $\begin{array}{c}\text { Direct } \\
\text { relaxation } \\
\text { of } \\
\text { arteriolar } \\
\text { smooth } \\
\text { muscle } \\
\end{array}$ & ++ & ++ & - & - & $\ldots$ & $\begin{array}{c}5-20 \mathrm{mg} \\
\text { bolus every } \\
15 \mathrm{~min}\end{array}$ & $\begin{array}{c}10-20 \\
\min \end{array}$ & $1-4 \mathrm{~h}$ & $\mathrm{SS}, \mathrm{ES}^{53}$ & $\begin{array}{l}\text { SS, } \\
\mathrm{CS}^{82}\end{array}$ \\
\hline $\begin{array}{l}\text { Nitropru } \\
\text { sside }\end{array}$ & $\begin{array}{c}\text { Releases } \\
\text { nitiric } \\
\text { oxide } \\
\end{array}$ & ++ & ++ & - & - & $\ldots$ & $\begin{array}{l}\text { Infusion of } \\
0.2 \text { to } 10 \mu \mathrm{g} \text {. } \\
\mathrm{Kg}^{-1} \cdot \mathrm{min}^{-1}\end{array}$ & $\begin{array}{c}\text { Within } \\
\text { Secon } \\
\text { ds }\end{array}$ & $\begin{array}{l}2-5 \\
\min \end{array}$ & $\begin{array}{c}\text { SS, CS, } 42 \\
\text { ES } 90\end{array}$ & $\begin{array}{c}\text { SS, } \\
\mathrm{CS}^{82}\end{array}$ \\
\hline $\begin{array}{l}\text { Nitrogly } \\
\text { cerine }\end{array}$ & $\begin{array}{c}\text { Releases } \\
\text { nitiric } \\
\text { oxide }\end{array}$ & + & $\ldots$ & $\cdots$ & - & $\cdots$ & $\begin{array}{l}20 \text { to } 400 \mu \mathrm{g} \\
\mathrm{min}\end{array}$ & $\begin{array}{l}1-2 \\
\min \end{array}$ & $\begin{array}{l}3-5 \\
\min \end{array}$ & & $\begin{array}{c}\text { SS, } \\
\text { CS }^{91}\end{array}$ \\
\hline $\begin{array}{c}\text { Nitropas } \\
\text { te }\end{array}$ & $\begin{array}{c}\text { Releases } \\
\text { nitiric } \\
\text { oxide } \\
\end{array}$ & + & $\ldots$ & $\ldots$ & - & $\ldots$ & $\begin{array}{c}0.2-0.4 \mathrm{mgh} \\
\text { up to } 0.8 \\
\text { mgh }\end{array}$ & $\begin{array}{l}1-2 \\
\min \end{array}$ & $\begin{array}{l}3-5 \\
\min \end{array}$ & SS, CS92 & $\begin{array}{c}\text { SS, } \\
\text { CS92 }\end{array}$ \\
\hline $\begin{array}{l}\text { Nicardip } \\
\text { ine }\end{array}$ & $\begin{array}{l}\text { Calcium } \\
\text { channel } \\
\text { blocker }\end{array}$ & plus & $\ldots$ & - & - & $\ldots$ & $5-15 \mathrm{mgh}$ & $\begin{array}{c}5-10 \\
\min \end{array}$ & $\begin{array}{c}0.54-4 \\
\mathrm{~h}\end{array}$ & SS, CS58 & $\begin{array}{c}\text { SS, } \\
\text { CS81, } \\
83\end{array}$ \\
\hline $\begin{array}{c}\text { Esmolol } \\
+\end{array}$ & $\begin{array}{c}\beta- \\
\text { Adrenergic } \\
\text { blocker }\end{array}$ & $\ldots$ & $\ldots$ & $\ldots$ & Plus & - & $\begin{array}{c}250 \mu \mathrm{g} \mathrm{kg} \\
\text { bolus } \\
\text { followed by } \\
25 \text { to } 300\end{array}$ & $5 \mathrm{~min}$ & $9 \mathrm{~min}$ & & SS \\
\hline $\begin{array}{c}\text { Enalapri } \\
\text { l* }^{*}\end{array}$ & $\begin{array}{c}\text { ACE } \\
\text { Inhibitor }\end{array}$ & $\ldots$ & $\ldots$ & plus & - & $\ldots$ & $\begin{array}{l}1.25-5 \mathrm{mg} \\
\text { every } 6 \mathrm{~h}\end{array}$ & $\begin{array}{c}15 \\
\min \end{array}$ & $1-4 \mathrm{~h}$ & $\begin{array}{c}\text { CS,93 ES } \\
53\end{array}$ & $\begin{array}{c}\text { SS, } \\
\text { ES94 }\end{array}$ \\
\hline
\end{tabular}

Table 1: CBF: Cerebral Blood Flow; SS: Scientific Statement; CS: Clinical study; ES: Experimental Study; ACE: AngiotensinConverting Enzyme; +: Increase or favorable effect; ++: Substantial increase or favorable effects; -: Decrease or negative effect; ...: No documented direct effect.

No conclusive evidence is present at the point to avoid ant particulars class of antihypertensive medication (including $\beta$-blocker ${ }^{96}$ ). In general, medication with slow onset of action, along half-ives, or those known to cause precipitous BP reduction (sublingual nifedipine ${ }^{96}$ ) should be avoided in the first 24 hours because they cannot be titrated to ensure controlled BP reduction.
*Data predominantly derived from other ACE inhibitors; +limited data available; +not derived from the stroke settings and unclear direct relevance.

In hypertensive encephalopathy treatment should be given like antihypertensive once structural etiology has been excluded. For patients without a history of hypertension, normal blood pressure parameters are 
appropriate, but for those with chronic hypertension, an abrupt return to $140 / 90 \mathrm{mmHg}$ may result in hypoperfusion owing to chronic vascular compensatory changes [1]. Close observation and intravenous antihypertensives are generally indicated. Nitroprusside is a good choice because of its effectiveness, rapid onset, and ease of adjustment [1].

In addition, intravenous dihydropyridine calciumchannel blocking agents and ACE inhibitors are also effective and easy to titrate and may have less-profound effects on cerebral vessels [15]. The underlying cause of the hypertensive episode should be sought. Prognosis in treated patients is generally excellent. Neurologic deficits usually recover completely within 2 weeks. Other than that, medical care for hypertensive retinopathy involves evaluation of secondary causes and appropriate medical management involving lifestyle changes and pharmacotherapy [15].

Treatment that can be given for eclampsia is magnesium sulfate which has been also shown decrease risk in maternal death without evidence of significant harm to the mother or baby [12]. Therefore, intravenous magnesium sulfate should be administered for seizure prophylaxis both during delivery and for 24 hours after delivery. Both phenytoin and diazepam are superior to prevent the recurrence of eclamptic seizures [13]. A range of regimens for magnesium sulphate exists where it is generally administered as a loading dose followed by a continuous infusion for 24 hours postpartum or following the last seizure. Further recurrent seizures can be treated with a further bolus of magnesium sulphate. Seizures which are unresponsive to magnesium sulphate can be treated with benzodiazepines or sodium amobarbital [13].

\section{Discussion}

In this study we found that age is not the matter of factor that anyone can say young children cannot be diagnosed as HTN. Because there are many studies has proven that young children nowadays are having hypertensive encephalopathy like seizures, acute hemiplegia and muscle weakness which is due to high BP. As a result, causes of HTN is varies from each and every individual as they are different genetically. HTN is also due to genetically predisposition but there is lack of research done on this matter. Besides that, age, gender, ethnic group, environmental factors, mental health, educational level, occupational factors and many more are reasons of having HTN. As HTN is a modifiable disease, so it can be controlled by taking medications like antihypertensive drugs. Most important thing in this condition is once a person diagnosed as HTN, it cannot be cured fully. Hypertensive patients can only be in control of BP throughout their life. There are several measures that have been found out in several studies to prevent and manage HTN. For instance, good dietary control, active in physical activities, good quality of sleep, avoid consumption of alcohol and smoking, steady mental health and also social health [16].

It is very important for a hypertensive patient to be in a very good control of their BP and drug compliance because HTN can lead to many complications like neuronal conditions, heart failure, myocardial infarction and also renal failure [2].

As this research study is more focus on neurological complications due to HTN, stoke, hypertensive neuropathy, hypertensive retinopathy and eclampsia are all related to neurological complications of high BP. But there is lack of research studies done on the topic of neurological complications of HTN. More research is done on HTN that causes coronary heart disease and also renal failure as they give less importance to neurological complications of HTN. North American studies have shown that hypertension is a major contributor to 500000 strokes (250000 deaths) and 1000000 myocardial infarctions (500000 deaths) per annum [4]. Stroke is one of the major and high prevalence neurological complications of HTN. Stroke Unit Trialist's Collaboration, done an important advance in stroke management which is the advent and development of specialized stroke services (stroke units) in the majority of developed countries [8].

These services are organized as specialized hospital units focusing exclusively on stroke treatment. Evidence from randomized trials shows that treatment in stroke units is very effective, especially when compared with treatment in general medical wards, geriatric wards or any other kind of hospital department in which no beds or specialized staff are exclusively dedicated to stroke care. This results in reduce early fatality (death within 12 weeks) by $28 \%$ and death by the end of year follow-up by $17 \%$ (relative risk reduction). Despite proven efficacy and cost-effectiveness, stroke unit care remains underused in almost all parts of the world.

So, in future further research studies need to be done to the neurological complications of HTN because this condition causes high mortality rate not only in Malaysia, also in other countries. Moreover, National surveys continue to reveal that hypertension is often not detected, 
diagnosed and is often inadequately treated [4]. Regarding this matter, the researchers should take this into account and need to proceed with research on how to diagnosed HTN as early as possible and also how to fully cure this condition. In this present situation, HTN and all its complications including neuronal conditions are under control by the therapeutic agents and also management $[1,17]$.

\section{Conclusion}

As a conclusion, this study highlights a serious situation as almost half of the people in the world including Malaysian aged more than 30 years have HTN. And of those, only half were aware of their hypertensive status, less than $40 \%$ were on treatment and few of them are controlled. Since HTN is a modifiable disease, it can be controlled and prevented. It is proven that neurological complications due to HTN, cause high mortality rate among people in the worldwide. Even though HTN can be controlled by antihypertensive drugs but the quality of life of a person is gone. Furthermore, there are still studies going on for the treatment and also management of HTN and its complications. Rehabilitation is one of the measurement can be done in neurologically affected patients due to HTN. Thus, public health measures, as well as individual interventions in primary care are crucial to reduce their risk of developing complications. Although nowadays the prognosis is good for hypertensive patients but improvements need to be done in treating and managing patients to decrease the incidence and mortality rate.

\section{References}

1. Johnston AS (2014) Neurological complications of hypertension. Aminoff's Neurology and General Medicine, $5^{\text {th }}(\mathrm{Edn}),. \mathrm{pp}: 119-145$.

2. Sharifian M (2012) Hypertensive Encephalopathy. Iran J Child Neurol 6(3): 1-7.

3. Richard A, Cuneo MD, John J Caronna M (1977). The neurologic complications of hypertension. Medical clinics of North America 61(3): 565-580.

4. Sear PF (2004) Hypertension: Pathophysiology and treatment. Continuing Education in Anesthesia, Critical Care \& Pain 4(3): 71-75.

5. Gareth Beevers GY (2011) The pathophysiology of hypertension. $4^{\text {th }}$ (Edn.), ABC of hypertension 322: 912-916.
6. Uhari M, Saukkonen AL, Koskimies O (1979) Central nervous system involvement in severe arterial hypertension of childhood. European Journal of Pediatrics 132(3): 141-146.

7. Richards A, Graham D, Bullock R (1988) Clinicopathological study of neurological complications due to hypertensive disorders of pregnancy 51(3): 416-421.

8. Qureshi AI (2008) Acute hypertensive response in patients with stroke: Pathophysiolgy and management. Circulation 118(2): 176-187.

9. Irawan Susanto MF (2018) Hypertensive Encephalopathy. (M. Helmi L Lutsep, Editor) Drugs \& Diseases.

10. Erden S, Bicakci E (April, 2012) Hypertensive Retinopathy: Incidence, Risk Factors, and Comorbidities. Clinical and Experimental Hypertension 34(6): 397-401.

11. Kean Theng, Oh M (2016) Ophthalmologic Manifestations of Hypertension. (SM Hampton Roy) Drugs \& Diseases.

12. Kattah AG, Garovic VD (2013) The Management of Hypertension in Pregnancy. Adv Chronic Kidney Dis 20(3): 229-239.

13. Kane SC, Dennis A, da Silva Costa F, Kornman L, Brennecke S (2013) Contemporary clinical management of the cerebral complications of preeclampsia. Obstet Gynecol Int pp: 1-10.

14. Widimsky, J. (2015). The role of arterial hypertension in the primary prevention of stroke. Acute Ischemic Stroke 58(2): 280-286.

15. Abdul-Razak S, Daher AM, Ramli AS, Ariffin F, Mazapuspavina MY, et al. (2016). Prevalence, awareness, treatment, control and socio demographic determinants of hypertension in Malaysian adults 16: 351

16. Naing C, Yeoh PN, Wai VN, Win NN, Kuan LP, et al. (2016) An analysis of trends from the National Surveys 1996 to 2011. Medicine (Baltimore) 95(2): e2417.

17. Aziz ZA, Lee YY, Ngah BA, Sidek NN, Looi I (2015). Acute Stroke Registry Malaysia, 2010-2014: Results from the National Neurology Registry. J Stroke Cerebrovasc Dis 24(12): 2701-2709. 
